\title{
A modest proposal
}

Pete Nowak

W e live in interesting times. Working in that interface between conservation and agriculture seems to vacillate between H.G. Well's The Time Machine, why are we still acting like it is the 1950s? and William Shakespeare's Comedy of Errors, exactly who is the conservationist? These times are interesting because we are still struggling with the legacies of the past, trying to deal with the dynamics of our rapidly changing world, and, albeit reluctantly, preparing for what appears to be a tumultuous future.

Besides interesting, these are also opportune times. It is within this swirling pool of uncertainty that a few bold decisions could set a positive course for conservation for years to come, much as H.H. Bennett did in his speech to the Congress in 1935. Unfortunately, that bold decision requires a vision derived from innovative, creative ideas learned as part of our conservation journey (Nowak 2011). Lessons from the past are important, but attempting to recreate the past in the present is not the best way to approach the future.

It is in this spirit that I would like to offer a modest proposal. Some may view this proposal as radical to legacies of the past and to current setting, but perhaps it is appropriate for the future.

\section{THE CHALLENGE}

Let me establish the context of this proposal without getting buried in statistics. We set goals to reduce rates of soil erosion to at least soil loss tolerances (T-values), and while significant progress has been made, some people suspect that recent grain market prices have those erosion rates climbing again. Ephemeral gully erosion, a process not considered in the calculation of erosion rates, appears to be rampant in the Midwest (Cox et al. 2011) and perhaps elsewhere. Protecting our soil remains largely an act of convenience, and

Pete Nowak is a professor of environmental studies in the Gaylord Nelson Institute for Environmental Studies at the University of Wisconsin-Madison, Madison, Wisconsin. unfortunately, most think like a banker rather than a plant root (Shaxson 2007).

We also set ambitious goals to reduce nutrient loads entering estuaries and coastal waters, but "dead zones" in those waters continue to expand in size. Market forces clearly trump conservation, and the federal hand of conservation compliance is overruled at the local level in a majority of violations. The number and extent of impaired surface waters increase each year despite countless hours of planning remedial efforts. We are slow to learn about the critical gap between planning and implementation, and one does not necessarily lead to the other. Even the metaphorical Lazarus appears to be dying again as Lake Erie, a poster child for an earlier environmental movement, reportedly is slipping into a state of hypereutrophication once again.

Further evidence suggests how degradation continues to mount across America's landscapes, but my purpose here is not to dwell on those challenges. It is to offer a modest proposal about how to address those challenges. Modest in the sense that it is not based on federal subsidies because, as I write this, funding for traditional, incentive-based conservation programs is being slashed to reduce national budget obligations. It is a perfect time to think creatively about the future rather than simply defend the status quo.

\section{THINIKING OUTSIDE THE BOX}

This modest proposal suggests one way to move beyond the institutional arrangements that emerged 80 years ago and explore a new and different approach to enhancing the resiliency of working landscapes. It is only one way. There are others, I am sure, but this modest proposal is different from what I hear being discussed today. This is what that overused cliché of "thinking outside the box" means. It is not easy, and one rarely gets it right on the first attempt.

Avoiding another iteration of "old wine in new bottles" is a challenge because we have trained and supported several generations of conservationists to think that the only approaches to conservation must begin at the national level, be based on some form of fiscal subsidy, and remain dependent on co-opting local conservation authorities who try to sell it to landowners. Innovation according to this standard template is really a misnomer-the overwhelming majority of ideas take on some form of a repetitive theme of paying individuals to engage in a behavior they might not otherwise practice. As a point of comparison, investigate the definition of bribery in any dictionary. Pandering to the land manager with a government check may be easy, but it is not innovative.

Yet, the belief that an amalgamation of government interests will provide local residents the knowledge, technical expertise, and financial resources needed to advance conservation is so pervasive that few ever climb out of the box and ask if there is another way. Do not interpret this as simply another appeal to local populism because I have observed many times that ignorance and incompetence are alive and well in local settings as well.

The fact of the matter is that lack of conservation across our agricultural landscapes is happening in situations dominated by market-based decisions: where rewards are based on performance, where optimizing performance is dependent on solving practical problems, and where peer pressure to be progressive remains a reality. Why ignore these endemic processes or try to overwhelm them with a subsidy? Why not build a program based on these processes? "Wait a minute," you are saying, "how is this different than programs already in place?" The big difference-and this is very important-is that my modest proposal would apply only to groups or neighborhoods of land managers rather than to the individual.

\section{HAIL TO THE INDIVIDUAL!}

If there is one unifying theme or foundation to our institutional arrangements over the past 80 years, it is the appeal to 
the economically rational individual as the basis to put conservation on the land. We assume it is the individual only who seeks to optimize profits, rationally evaluates production versus conservation trade-offs, and engages in conservation behaviors. We design policy so it is the individual who legally enters into contractual arrangements regarding conservation programs. It is also the individual who is the focal point of educational and outreach efforts in the conservation arena. There are hundreds if not thousands of scholarly articles examining the adoption of conservation practices by individuals. We have created a very effective set of blinders that only allows us to see the individual when it comes to conservation.

This homage to the individual is consistent with our culture, but it also ignores the fact that it is the group (i.e., corporation, cooperative, or complex organization) that makes our world go around. Individuals are important, but the whole is always greater than the sum of the parts. An organized group of individuals (e.g., a team) will always be more effective than the aggregated efforts of a similar-sized group of independent individuals. We have forgotten the lessons of Coon Creek and other early conservation initiatives where the pioneers of our profession worked with groups of farmers and ranchers.

\section{A MODEST PROPOSAL}

My modest proposal goes beyond simply geographically targeting a group, neighborhood, or local community of land users. We must empower individuals to work together to solve local natural resource problems. Creating conservation cooperatives-organized on the basis of high-value, small-scale watershedswhere members will work together to solve local natural resource management problems can achieve this. Unfortunately, the mechanism for a group approach to solving conservation problems has been lacking due to our ongoing emphasis on the individual.

Recent activities regarding the Clean Water Act have created an opportunity for a group approach as some public water works need to invest in infrastructure that reduces nutrient loadings to public waters.
Nutrient trading is the idea that paying individual farmers to practice nutrient management is a more cost-effective method than installing expensive equipment in public water works facilities. Although the concept is sound, practical implementation is bogged down by the complexity of accountability measures for individual performance. Added to that is the problem that nonparticipants can negate the gains of participating farmers, and segmenting legacy impacts from recent reductions is a coarse estimate at best. It is a sound idea being lost due to the focus on the rational individual. Let us take the same concept and apply it to a group of contiguous landowners and managers.

Nutrient trading provides the opportunity to explore the potential efficacy of conservation cooperatives formed on a watershed basis. We would begin in areas where there is opportunity for nutrient trading between public water works in watersheds dominated by agricultural land uses. A high-priority, small-scale watershed would be identified-perhaps using the analytic capabilities of USDA Natural Resources Conservation Service personnel-where most if not all of the landowners in the watershed could be persuaded to join the cooperative. This cooperative, a legal entity owned and democratically controlled by its members, would be organized to serve the members:

- Owners of land within this boundary would be issued shares proportionate to the amount of land they control. The shares would be tied to the land so they could not be traded or sold independent of the land. The idea is to allow conservation to add value to the land, prompting further investment in conservation.

- The organization would operate like any other cooperative where members elect officers, develop plans of work, and monitor financial activities.

- The public water works would issue payments for nutrient reductions to the cooperative. The cooperative would subtract costs and other operating expenses, and then return remaining income to the members.
- The cooperative would be responsible for identifying the need for conservation in site-specific settings, installing practices, insuring appropriate maintenance takes place, and assessing or measuring the impacts of those efforts. Some responsibilities would be met in the form of contracts with technical service providers or local conservation authorities. Legitimate costs of getting conservation on the ground would be borne by the cooperative as part of its annual operating expenses.

- A critical issue would be the monitoring of changes in nutrient loadings from the watershed because this would serve as the basis for payment, or withholding of payment, to members of the cooperative. The cooperative would have to contract with a certified third party (e.g., US Geological Survey) to provide monitoring data to the public water works.

There are multiple advantages to this approach. It would mobilize peer pressure to the extent that public agencies never could achieve with past efforts on rational individuals. Payments to the entire cooperative would be reduced if a few landowners engage in inappropriate production practices in vulnerable places or times. The scope, format, or strength of the resulting peer pressure is unknown, but anecdotal evidence suggests it could be persuasive. Besides peer pressure, there would be an explicit market-based incentive to use the problem-solving knowledge of land managers to reduce nutrient exports. The payment system would have land managers working together because payments would be based on the group's performance. Landowners would quickly recognize that the size of the incentive depends on collaborative activities needed to solve nutrient management problems. Innovative solutions and approaches would be tried, and while all may not be by the book (i.e., field office technical guides), the real gain is that you would have farmers or ranchers working together to improve water quality. Federal agencies would revert to the original mission envisioned in the three-way memorandum of understanding with local residents inviting them to provide technical assis- 
tance as determined by the local residents. Conservation districts, the corollary of the "mom and pop" gas station or grocery store in today's conservation arena, would have to learn how to adapt to these conservation cooperatives or suffer the same fate as the aforementioned gas stations and grocery stores.

A conservation cooperative built around nutrient trading would be based on market processes. Rewards would be linked to performance, local problemsolving skills would be supported, and peer pressure would play a critical role. Absentee landlords and farm management firms would probably require tenants to participate because of the reward system. Most importantly, members of the cooperative would begin to build their resource management knowledge and skills, thereby fulfilling that critical first step of beginning the conservation journey. A conservation cooperative has the potential of going far beyond enhancing public waters.

\section{A PARTING OBSERVATION}

We all understand the processes behind the tragedy of the commons (Hardin 1968). For three-quarters of a century, we have tried to counter the irrational rationality of that situation by providing subsidies to individual members of the commons. Yet, it seems we could never get enough to participate, offer enough of a subsidy, or induce enough protection. Why not organize the members of the commons into a cooperative while creating a market to enhance the quality of the commons (i.e., public waters)? We can begin with water through nutrient trading, but later, as we become more proficient in valuing ecological goods and services, and if this modest proposal proves to have value, the approach could be expanded to other resource management areas.

Some may say this is not the best time to introduce a novel idea into the political process. Political conflict over resource management is not new, but the emotionladen politics of confrontation in an era of instantaneous communication can create gridlock or uncertainty in any conservation initiative. Therefore, it is important to emphasize that this is not a statement regarding the current political situationit is simply a modest proposal to advance the conservation agenda. There are many details that would have to be worked out prior to beginning a few trial efforts of this modest and, most importantly, nonpartisan proposal. It is an idea that probably will not work everywhere, but it has sufficient potential that it could be employed in appropriate locations.

The cooperative concept should not be viewed as competing with existing programs. The intent is to provide another tool for the conservation toolbox that might complement other approaches. Something similar is being tried in the US Department of the Interior's Bureau of Reclamation Desert Landscape
Conservation Cooperative that focuses on water conservation. Now we need the US Environmental Protection Agency, USDA, a provincial authority, or even a local conservation agency to pick up this idea and make it happen.

The important aspect of this modest proposal is that it moves us away from relying on the "economically rational individual" as the conceptual core of our conservation efforts and begins to explore the potential of other market mechanisms based on cooperative approaches. It does not reject the proud history of the conservation community, but actually returns to the approaches used in those early efforts. It is a modest proposal worth discussing, and, for those subversive conservationists (Nowak 2009) wanting to solve problems, a proposal worth trying.

\section{REFERENCES}

Cox, C., A. Hug, and N. Bruzelius. 2011. Losing Ground. Washington, DC: Environmental Working Group. http://www.ewg.org/ losingground/.

Hardin, G. 1968. The Tragedy of the Commons. Science 162(3859):1243-1248.

Nowak, P. 2009. The subversive conservationist. Journal of Soil and Water Conservation 64(4):113A-115A.

Nowak, P. 2011. The conservation journey. Journal of Soil and Water Conservation 66(3):61A-64A.

Shaxson, F. 2007. Think like a root, think like a river. Journal of Soil and Water Conservation 62(5):86A-87A 